\title{
Tidal Stream vs. Wind Energy: The Value of Cyclic Power When Combined with Short-Term Storage in Hybrid Systems
}

\author{
Daniel Coles $^{1, *(\mathbb{D})}$, Athanasios Angeloudis ${ }^{2}\left(\mathbb{D}\right.$, Zoe Goss $^{3} \mathbb{D}$ and Jon Miles ${ }^{1}(\mathbb{D}$ \\ 1 School of Engineering, Computing and Mathematics, Faculty of Science and Engineering, University of \\ Plymouth, Plymouth PL4 8AA, UK; j.r.miles@plymouth.ac.uk \\ 2 Institute for Infrastructure and the Environment, School of Engineering, The University of Edinburgh, \\ Edinburgh EH8 9YL, UK; a.angeloudis@ed.ac.uk \\ 3 Department of Earth Science and Engineering, Imperial College London, London SW7 2AZ, UK; \\ z.goss15@imperial.ac.uk \\ * Correspondence: daniel.coles@plymouth.ac.uk
}

Citation: Coles, D.; Angeloudis, A, Goss, Z., Miles, J. Tidal Stream vs. Wind Energy: The Value of Cyclic Power When Combined with Short-Term Storage in Hybrid Systems. Energies 2021, 14, 1106. https://doi.org/10.3390/en14041106

Academic Editor: Guillou Sylvain

Received: 15 January 2021

Accepted: 14 February 2021

Published: 19 February 2021

Publisher's Note: MDPI stays neutral with regard to jurisdictional claims in published maps and institutional affiliations.

Copyright: (c) 2021 by the authors. Licensee MDPI, Basel, Switzerland. This article is an open access article distributed under the terms and conditions of the Creative Commons Attribution (CC BY) license (https:// creativecommons.org/licenses/by/ $4.0 /)$.

\begin{abstract}
This study quantifies the technical, economic and environmental performance of hybrid systems that use either a tidal stream or wind turbine, alongside short-term battery storage and back-up oil generators. The systems are designed to partially displace oil generators on the island of Alderney, located in the British Channel Islands. The tidal stream turbine provides four power generation periods per day, every day. This relatively high frequency power cycling limits the use of the oil generators to $1.6 \mathrm{GWh}$ /year. In contrast, low wind resource periods can last for days, forcing the wind hybrid system to rely on the back-up oil generators over long periods, totalling $2.4 \mathrm{GWh}$ /year ( $50 \%$ higher). For this reason the tidal hybrid system spends $£ 0.25$ million/year less on fuel by displacing a greater volume of oil, or $£ 6.4$ million over a 25 year operating life, assuming a flat cost of oil over this period. The tidal and wind hybrid systems achieve an oil displacement of $78 \%$ and $67 \%$ respectively (the same as the reduction in carbon emissions). For the wind hybrid system to displace the same amount of oil as the tidal hybrid system, two additional wind turbines are needed. The ability of the battery to store excess turbine energy during high tidal/wind resource periods relies on opportunities to regularly discharge stored energy. The tidal hybrid system achieves this during slack tides. Periods of high wind resource outlast those of high tidal resource, causing the battery to often remain fully charged and excess wind power to be curtailed. Consequently the wind hybrid system curtails $1.9 \mathrm{GWh}$ /year, whilst the tidal turbine curtails $0.2 \mathrm{GWh}$ /year. The ability of the tidal stream turbines to reduce curtailment, fuel costs and carbon emissions may provide a case for implementing them in hybrid systems, if these benefits outweigh their relatively high capital and operating expenditure.
\end{abstract}

Keywords: tidal stream energy; wind energy; hybrid system; intermittency; Alderney

\section{Introduction}

The tidal stream energy resource is cyclic in nature, which has been highlighted as a major benefit over other intermittent renewable energy resources [1-4]. However, the potential benefits of cyclic power generation remain only loosely defined. To establish tidal stream energy's future role in the energy generation sector, it is important to quantify these potential benefits to provide a full picture of its offering. In this study we quantify the technical, economic and environmental performance of a tidal hybrid system (THS) that uses a tidal stream turbine as the primary source of power in a system that also contains short-term battery storage and back-up oil generators. The THS performance is compared to an equivalent wind hybrid system (WHS) that uses a wind turbine instead of a tidal stream turbine. The hybrid systems are designed to help reduce oil generator use on the island of Alderney, in the Channel Islands. 
Many small islands and remote communities rely on oil or diesel generators to produce electricity. These technologies emit carbon into the atmosphere, are costly and can cause energy security challenges if fossil fuels are imported. Net-zero carbon emission targets are driving a need to transition to renewable energy technologies for electricity supply. Hybrid systems, typically made up of renewable energy technology, an energy storage system and back-up power supply, are becoming viable options in regions where connection to utility grid supply is prohibitive. For example, the Isle of Eigg in the UK has transitioned from diesel generators to a renewable energy hybrid system that includes hydroelectric generators, wind turbines, solar photovoltaic (pv) panels, and a battery [5]. Diesel generators are used for back-up, contributing approximately $5 \%$ of the electricity supply. The most suitable renewable technologies for a particular region will depend mainly on the availability of renewable energy resource(s), as well as other considerations such as cost of energy and environmental impact.

To date, research has focused mainly on hybrid systems that use a combination of wind turbines, solar pv panels, battery storage and back-up diesel/oil generators, e.g., [6-10]. This is reflective of the prevalence of wind and solar resources globally, along with the low cost of wind turbines and solar pv panels. Most renewable energy technologies are non-dispatchable, so energy storage can be used to help meet demand during low renewable energy resource periods. Typically back-up diesel/oil generators are used to provide a small proportion of the total energy demand, since the non-dispatchable nature of renewable power means that the total demand cannot be met without oversizing the renewable energy capacity and storage [11], which would result in exorbitantly high cost. Combining intermittent technologies such as wind and solar pv can help reduce fluctuations in overall renewable power production, where wind power tends to be greatest at night and during winter months, whilst solar pv power is greatest during summer days, for example [12]. This reduces battery storage requirements [13] and/or reduces the need to oversize the installed renewable capacity for demand to be met, thereby reducing the overall cost of energy [10]. Regardless of this, it is not unusual for energy to be curtailed during periods of high renewable energy resource when the battery is fully charged.

Recent research has considered alternative renewable energy technology combinations, such as wind-wave hybrid systems, e.g., $[11,14,15]$. It is shown that in the North Sea, there is a lag between the wind and wave energy resource, since the wave resource targeted by most wave generators is wind generated. This is beneficial as it helps smooth out the overall wind-wave power profile, thereby reducing reliance on back-up generation to prolong autonomous operation of the hybrid system.

The tidal stream energy industry is at a relatively early stage of development, but interest is growing in using the technology in hybrid system applications. Potential tidal sites on the European continental shelf exhibit semi-diurnal tidal behaviour, where the principle tidal constituent has a wavelength of approximately $12.4 \mathrm{~h}$ in which a flood-ebb cycle is completed, with slack water separating the flood and ebb tide. This results in four separate power generation periods per day. The cyclic, predictable nature of tidal stream power generation is generally acknowledged to offer benefits to grid integration over alternative variable renewable energy generation technologies [16-19]. Bryden et al [2] conducted an investigation into the use of a tidal stream turbine and flywheel to achieve firm power. This work highlighted the effectiveness of short term storage to help achieve this goal, as a result of the cyclic nature of tidal stream energy supply. Clarke et al. [1] also investigated the ability of tidal stream power to provide firm power, concluding that a complimentary technology such as pumped storage or phased operation of a conventional hydro power plant is needed. Barbour et al. [3] investigated the optimal properties of a storage system to provide either demand-matching or baseload output when combined with a tidal stream turbine. Results demonstrate that the system can provide significant benefits over a tidal stream turbine operating in isolation, such as reduced curtailment in transmission constrained applications. The techno-economic viability of a hybrid system at Digby Neck in the Bay of Fundy, Canada was investigated by Manchester et al. [4]. The 
system used a 0.9 MW wave energy converter, a 0.5 MW tidal stream energy converter and an energy storage system. The study investigates the financial case for increasing battery storage duration, which reduces curtailment to increase revenue from energy sales, but increases the capital cost of the battery.

Industrial applications of tidal stream hybrid systems are also starting to emerge at small scale. The tidal stream energy company Nova Innovation have integrated their $0.4 \mathrm{MW}$ Shetland tidal stream turbine array with a Tesla battery to provide a base-load tidal power station [20]. Nova Innovation have also received funding from the Welsh Government for a project to power Barsdey Island with tidal stream turbines and battery storage [21]. The European Marine Energy Centre, based on Orkney, Scotland, has announced that it will combine tidal stream power with a $1.8 \mathrm{MWh}$ flow battery to power its hydrogen production plant [22].

It is acknowledged that the hybrid systems considered in this study are not likely to be reflective of the optimal hybrid system for Alderney. In reality, a combination of renewable energy technologies used in the same hybrid system may be more suitable. Instead, this study aims to provide an initial insight into the technical, economic and environmental benefits tidal stream energy can provide in hybrid systems, specific to Alderney. In doing so, this research provides tangible evidence of the benefits tidal energy's cyclic power profile can provide to grid integration, system cost and carbon emissions, whilst also helping to inform the optimal hybrid system design in future work. Importantly, this study updates previous research investigating hybrid systems on Alderney, through improved hydrodynamic modelling of the tidal resource and the implementation of current turbine design (e.g., rotor diameter). These are two areas that can impact upon the magnitude of tidal power generation, and hence the techno-economic viability of the technology significantly. Novelty is provided by presenting a direct comparison of the tidal and wind hybrid system behaviour, using Alderney's tidal and wind energy resource, enabling the technical, economic and environmental performance of the hybrid systems to be compared directly.

\section{Remote Electricity Systems}

Alderney is an example of a small, remote island, surrounded by a strong tidal stream energy resource [23]. The tidal stream resource is accelerated between Alderney and the mainland. The hydrodynamics are typical of the tidal stream energy resource located close to many islands and remote coastal sites around the world. Figure 1a shows regions that exhibit these properties around the UK and France. As discussed, some of the sites have already explored hybrid systems to help replace fossil fuel technologies, such as the Shetland Islands, the Orkney Islands, the Isle of Eigg and Bardsey Island. All of the sites identified are either cut off from a utility scale grid or are grid constrained, limiting the import and export of electricity. Many more islands around the world exhibit these characteristics, including the Faroe Islands in the north Atlantic ocean [24] to the Goto islands in Japan $[25,26]$. Figure $1 \mathrm{~b}$ shows the location of Alderney in the Channel Islands. The location of the wind resource data extraction point, Alderney airport and the tidal stream turbine are also shown. These are discussed with respect to the inputs to the hybrid system models in Section 3. Whilst this study focuses on hybrid system applications in Alderney, the investigation has relevance to these other off-grid/constrained grid regions that exhibit a high tidal stream energy resource. Site specific studies of each area are necessary to establish the optimal solutions for replacing fossil fuel technologies. This work aims to inform future studies of the benefits tidal stream energy can provide as part of a hybrid energy system. 
(a)

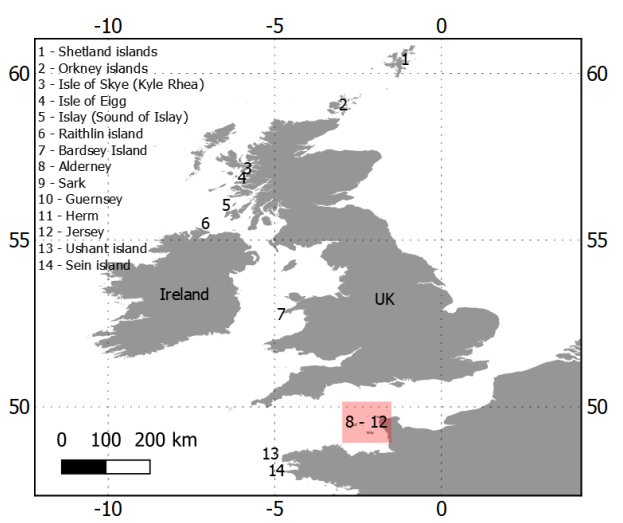

(b)

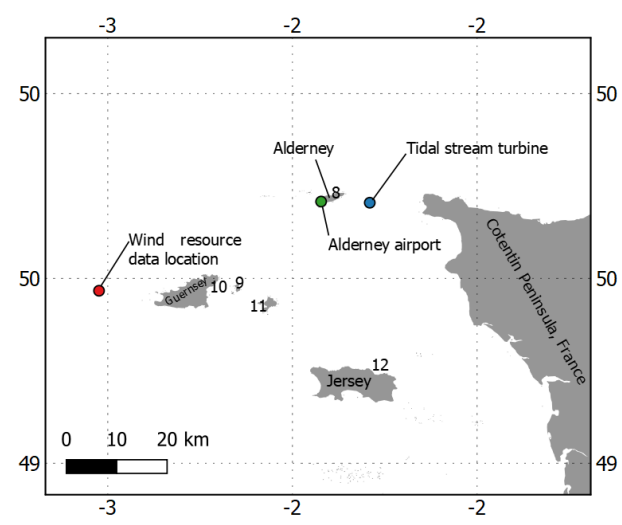

Figure 1. Location of (a) remote off-grid/grid constrained areas of high tidal stream energy resource in the UK and France, and (b) the location of Alderney in the Channel Islands.

Alderney's annual electricity demand is approximately 7.3 GWh, based on 2010 figures [27]. In general the instantaneous demand fluctuates between 0.4-1.1 MW, with peaks of between 1.3-1.65 MW during peak tourism periods in the summer months. The majority of the demand is from residential buildings, small businesses and the hospital, with no major industrial loads. Electrical power generation is provided by oil generators, with an annual demand of 2.2 million litres [28]. The island has three new $2 \mathrm{MW}$ generators, and four older generators $(2 \times 750 \mathrm{~kW}$ and $2 \times 450 \mathrm{~kW}$ systems), giving a total capacity of $8.4 \mathrm{MW}$. At times of peak demand generators can be run in parallel.

For maintenance, the oil generators require an overhaul every $9000 \mathrm{~h}$, at a cost of $£ 50,000-60,000$ /generator, and a major overhaul every $27,000 \mathrm{~h}$, at a cost of $£ 120,000$ /generator. The oil is stored in 13 tanks, providing enough storage for three weeks of reserve, on top of the forecast demand for that period. The oil tanks are refurbished every seven years at a cost of $£ 25,000 /$ tank. Fuel costs fluctuate and are high relative to other fuels, resulting in high energy prices. Electricity is provided by Alderney Electricty Ltd (AEL), a not-for-profit electricity provider, at a price of approximately $0.31 \mathrm{E} / \mathrm{kWh}$. Since no profits are made, the electricity price is reflective of the cost of electricity production. Based on an annual electricity supply of $7.3 \mathrm{GWh}$, the total cost to provide this with oil generators is approximately $£ 2.29$ million. It is estimated that 4745 tonnes $\mathrm{CO}_{2}$ equivalent could be prevented by replacing oil with alternative renewable technologies for electricity generation [28], based on a carbon footprint of oil generators of $650 \mathrm{gCO}_{2} \mathrm{eq} / \mathrm{kWh}$ [29].

Consideration has been given to replace Alderneys's reliance on oil with alternative fuel sources. Historically, commercial scale wind energy has been believed to provide the cheapest solution, with 2-3 turbines able to meet the electricity and heating demand of the whole island [30]. Concerns over the visual impact of wind and surface piercing tidal turbines, and their impact(s) on the bird watching industry, have been raised [28]. Balsells et al. [31] assessed different renewable technology options for Alderney, including solar pv, onshore wind, tidal stream, and biomass. The study provided a range of different options depending on the priorities of the island. The tidal system displaced the most oil out of the technologies considered, resulting in the largest reduction in greenhouse gas emissions. However, the tidal system was dismissed on the grounds of cost. The estimated capacity factor of the tidal turbines was 0.2 , which is around half that of the capacity factor cited from operational turbines [32]. This implies the tidal turbines were either located in a low resource region, and/or inappropriately sized for the resource.

Utility scale tidal stream energy development has also been considered within Alderney's territorial waters. The Alderney Commission for Renewable Energy (ACRE) commissioned a strategic assessment of tidal energy and its impacts on the island in 2014 [28]. The assessment considered $1 \mathrm{GW}$ and $3 \mathrm{GW}$ arrays to evaluate the overall economic and environmental benefits to full scale development with energy export to France and/or the UK. The study concluded that the cost of supplying the bulk of the islands energy demand, 
excluding transport, would be three times the oil saving, based on 2006 pricing. The study does not appear to consider storage options for maximising the use of tidal power to meet demand. The assessment is based on a $16 \mathrm{~m}$ rotor diameter turbine, which may result in poor performance relative to more modern, larger devices. For example, developments in tidal turbine design have transitioned to dual-rotor, floating devices that increase swept area from $201 \mathrm{~m}^{2}$ (16 m rotor diameter rotor) to $628 \mathrm{~m}^{2}$ (20 m dual rotor), an increase of over $200 \%$. In light of the limitations of previous studies, there are grounds to re-assess the viability for Alderney to install a tidal stream energy hybrid system.

\section{Methods}

\subsection{Hybrid System Overview}

This study considers hybrid systems that use either a tidal stream turbine or onshore wind turbine, along with lithium-ion battery storage and back-up oil generators. These are referred to as the Tidal Hybrid System (THS) and Wind Hybrid System (WHS) respectively. A schematic diagram of the hybrid systems is shown in Figure 2. The tidal/wind turbines are used as the primary source of power generation. The DC bus couples the power from the turbines and the battery in order to supply the grid, or supply the battery with turbine power. An AC/DC converter is used between the turbines and the DC bus to provide the DC bus and the battery with DC power. The DC/AC converter between the DC bus and the grid is used to provide grid compliant AC electricity.

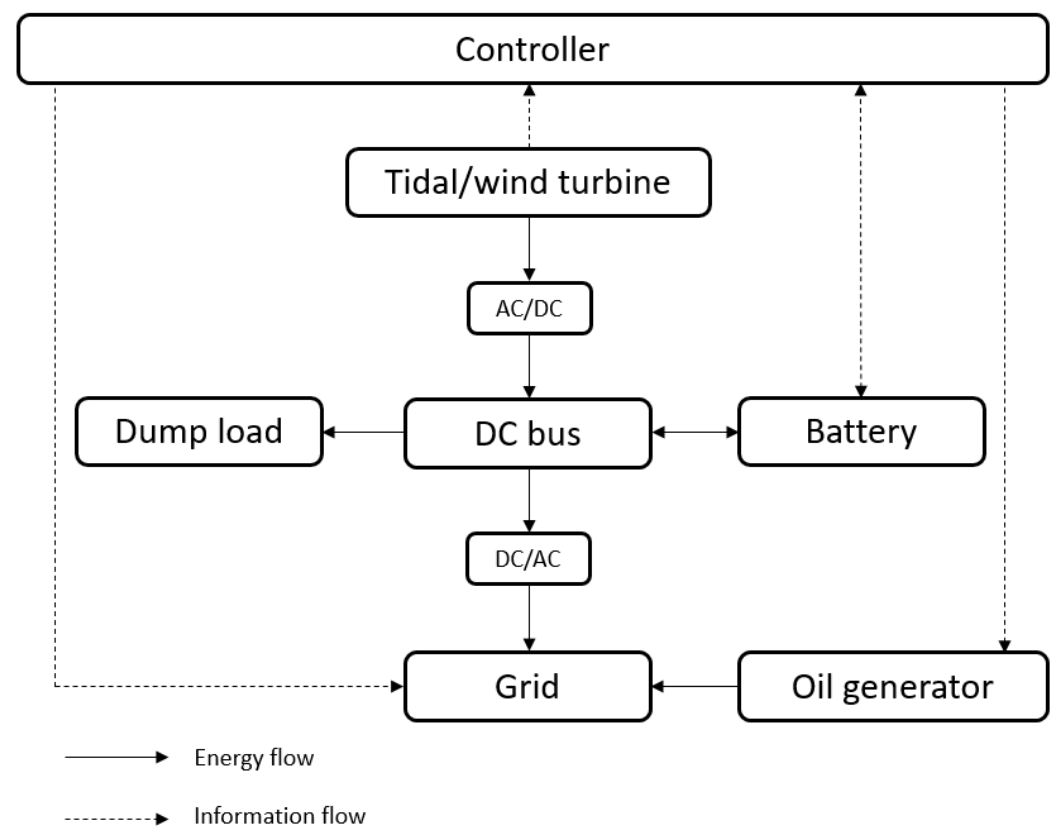

Figure 2. Schematic of the tidal/wind hybrid systems.

At times when renewable power generation exceeds demand and the battery has spare capacity, excess turbine power is used to charge the battery. This is illustrated in Figure 3a, where system components that are being used are shown in black, and components that are redundant are shown in grey. Arrows show the direction of power flow between components. If the battery is already fully charged during these periods, the excess turbine power is wasted through a dump load (Figure 3b). This has the same result as curtailing the turbine, in that the turbine energy is not used. When the turbine power falls below the demand, the battery is used to meet the shortfall if it is sufficiently charged (Figure 3c). In this case the tidal/wind turbine box appears dashed, to indicate that the turbines could be either generating or not in this scenario. If the battery is not sufficiently charged during these periods, the oil generators are used (Figure 3d) to meet demand. 
(a)

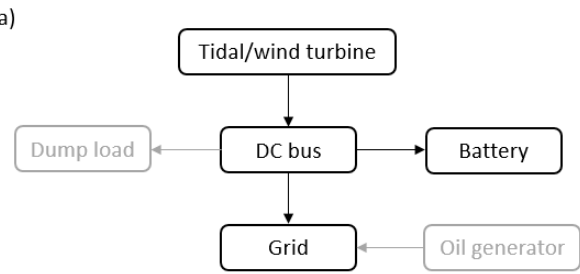

(b)

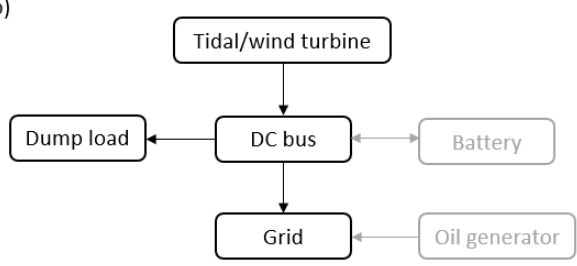

(c)

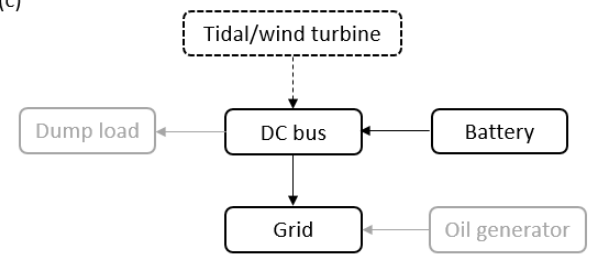

(d)

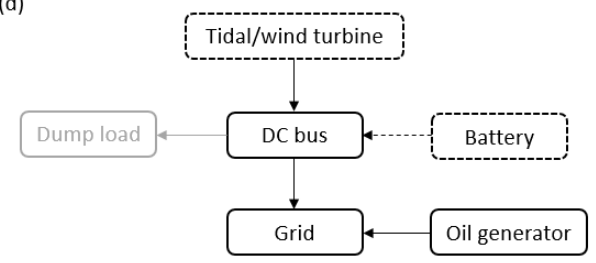

Figure 3. Illustration of the hybrid system operating schedules.

\subsection{Hybrid System Modelling}

A hybrid energy system model was built to simulate the power flows between the hybrid system components. The annual tidal power profile was derived using depth averaged tidal flow speeds, obtained from a validated 2D hydrodynamic model of the English Channel. The flow speeds were obtained at $10 \mathrm{~min}$ temporal resolution from the model run for the whole of 2013. Details of the model setup and validation are presented in Goss et al. [33]. The tidal stream turbine was located in Alderney Race at latitude, longitude coordinates $49.710747^{\circ},-2.10560^{\circ}$ (location shown in Figure 1b). The depth at the tidal turbine location was $39 \mathrm{~m}$ at lowest astronomical tide, with peak depth averaged flow speeds of $3 \mathrm{~m} / \mathrm{s}$. These conditions were favourable from an energy yield perspective, as it permitted a large rotor device to be placed in a high energy location. The depth averaged tidal flow speeds were converted to hub height flow speeds using Equation (1), which accounted for the boundary layer shear by assuming a $\frac{1}{7}$ th power law profile [34]

$$
u_{t}=u_{m}\left(\frac{h_{t}}{h_{m}}\right)^{\frac{1}{7}}
$$

where $u_{t}$ is the flow speed at the hub height of the rotors, $u_{m}$ is the flow speeds at the modelled height, $h_{t}$ is the hub height and $h_{m}$ is the measured height. The turbine power was calculated using Equation (2) [35]

$$
P=\min \left(\frac{1}{2} \rho u^{3} C_{p} A, \frac{1}{2} \rho u_{r}^{3} C_{p} A\right)
$$

where $P$ is turbine power, $\rho$ is the density of air or seawater, $u$ is the hub height flow speed, $u_{r}$ is the rated speed of the turbine, $c_{p}$ is the power coefficient equal to 0.41 [32] and $A$ is the swept area of the rotor(s). The power was capped at the rated speed of the turbine using blade pitch regulation.

The wind power profile was derived using $10 \mathrm{~m}$ height wind speeds obtained from the NOAA-CIRES-DOE Twentieth Century Reanalysis Version 3 data set [36], also over 2013. The data set was obtained from latitude, longitude coordinates $49.47^{\circ},-2.81^{\circ}$, located offshore to the west of Guernsey (location shown in Figure 1b). Based on wind measurements at Alderney airport (location also shown in Figure 1b), the average annual wind speed was $6.7 \mathrm{~m} / \mathrm{s}$ at $10 \mathrm{~m}$ height, with a variation slightly higher than $30 \%$ [37]. The average wind speeds from the reanalysis data exceeded this, and is most likely because the data were obtained from a higher energy, offshore location. The wind speeds were reduced to achieve a mean value of $6.7 \mathrm{~m} / \mathrm{s}$, thereby bringing them inline with mean 
onshore measurements on Alderney. Wind speeds were converted to hub height values using Equation (1). Wind power was calculated using Equation (2), using $\rho=1.225 \mathrm{~kg} / \mathrm{m}^{3}$ ).

The battery was based on the Tesla Megapack, which had a charge/discharge capacity of 1.5 MW, and a storage capacity of $3 \mathrm{MWh}$ (i.e., $2 \mathrm{~h}$ ) [38]. We assumed that the depth of discharge of the battery was $100 \%$ and that the battery did not degrade over time.

Alderney's electricity demand profile was inferred from a UK wide electricity demand profile provided by the Elexon Portal [39] and Sheffield University [40], and accessed through the G.B National Grid Status website [41]. The demand profile was scaled down so that the annual electricity demand met that of Alderney (7.3 GWh). This approach assumes the scaled-down national demand profile is representative of the Alderney demand. Alderney's specific demand characteristics such as the elevated summer demand driven by tourism are not captured at high accuracy, which may introduce some error in annual system performance estimates, but this is expected to be relatively small.

Initially the rated power, rotor diameter and hub height of the tidal stream turbine and wind turbine were sized so that their annual energy yield came close to the annual electricity demand of Alderney, of $7.3 \mathrm{GWh}$, whilst keeping the rated power, rotor diameter and hub height within the bounds of modern tidal stream/wind turbines. Both the tidal stream and wind turbine have a rated power of $1.5 \mathrm{MW}$. This allowed compatibility of both systems with the same 1.5 MW battery. The tidal stream turbine was based on the Orbital Marine Power, a floating, dual rotor device with rotor diameters of $20 \mathrm{~m}$, a total swept area of $630 \mathrm{~m}^{2}$ and a hub height of $24 \mathrm{~m}$. The wind turbine was based on a General Electric 1.5 MW series device, with a rotor diameter of $83 \mathrm{~m}$ and a hub height of $80 \mathrm{~m}$. These turbine specifications resulted in an annual energy yield of $6.3 \mathrm{GWh}$ and $6.8 \mathrm{GWh}$ respectively.

The THS and WHS performance was quantified based on multiple indicators. These include the level of oil displacement as a result of replacing the oil generators as the primary power source. The oil cost saving was also calculated, based on an assumed project life of 25 years and an all-in cost of electricity produced by oil generators of $31 \mathrm{p} / \mathrm{kWh}$. The reduction in carbon emissions from oil displacement was calculated, based on a carbon footprint of oil generators of $650 \mathrm{gCO}_{2} \mathrm{eq} / \mathrm{kWh}$ [29]. Curtailment of turbine energy was also calculated. This provided an indication of the level of autonomy of the tidal stream/wind turbine and battery in meeting demand. The sensitivity of system performance to battery storage capacity was also investigated, using a storage range of 1-7 MWh.

\section{Results}

\subsection{Tidal/Wind Power Resource}

Figure 4 shows the annual (a) tidal and (b) wind power generation time series, alongside (c) Alderney's electrical power demand. Tidal power generation was highest during spring tides, when the tide generating force was greatest as a result of alignment between the sun, Earth and moon [42]. During these spring tide periods the tidal turbine regularly reached its rated power of $1.5 \mathrm{MW}$, thereby exceeding the demand. Neap tides exhibited lower flow speeds, since the tide producing force reduced with mis-alignment between the Sun, Earth and Moon. Turbine power was proportional to flow speed cubed, so the maximum tidal power during these neap periods fell significantly, to below $0.5 \mathrm{MW}$ (i.e., below the demand). The spring-neap cycle occurred approximately every 14 days. The daily variations in tidal power and demand are not visible in Figure 4, but are presented and discussed in due course (Figure 5).

The annual wind power generation profile was stochastic, with relatively high levels of power generation observed around the winter months. This was caused by the jet stream, which tended to track further south during winter months when the temperature difference between the equator and the poles was greatest [43]. Alderney's electricity demand, based on the national demand profile, showed seasonal variation, with greatest demand during winter days when greater indoor activity and electric heating contributed 
to a higher electricity demand. As discussed this did not capture the peak summer demand that Alderney experienced.

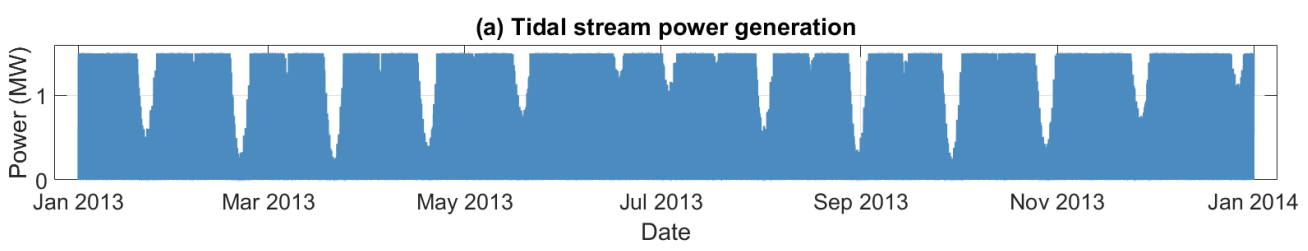

(b) Wind power generation

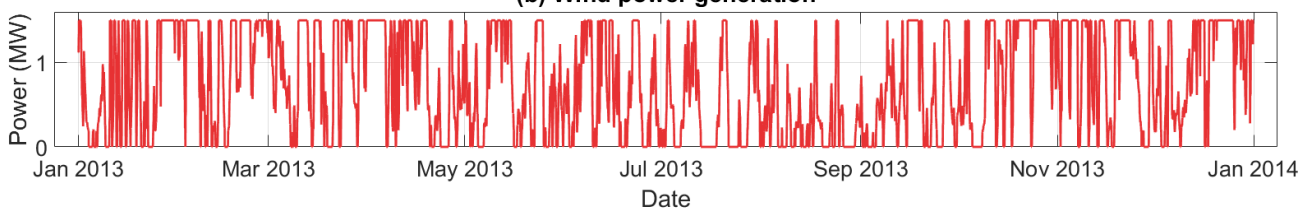

(c) Demand

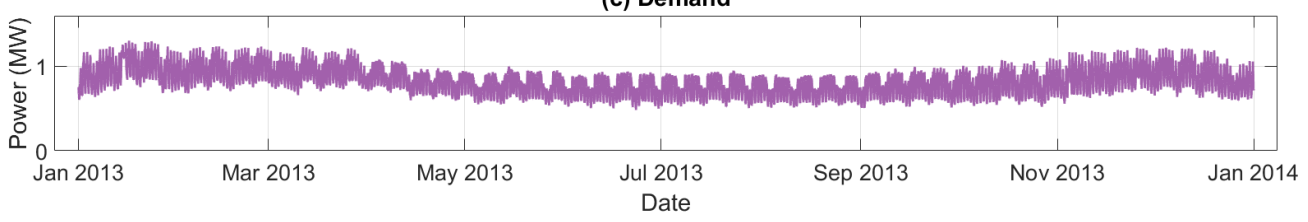

Figure 4. Annual power generation time-series from the (a) tidal stream turbine and (b) wind turbine, and (c) Alderney demand.

Figure 5 shows a typical 2 week tidal and wind power generation time series, along with Alderney's demand profile. During the 2 week period, the tidal turbine produced $200 \mathrm{MWh}$, and the wind turbine produced $280 \mathrm{MWh}$. The tidal power time series exhibited four power cycles per day, with each period of power generation separated by slack tide. Once the tidal flow speed exceeded the rated speed of the turbine, the turbine power was maintained at $1.5 \mathrm{MW}$ (i.e., rated power) through blade pitch regulation. During spring tide, these rated power periods lasted $2-3 \mathrm{~h}$, with power exceeding the Alderney demand. The daily capacity factor of the turbine during spring tide periods was around 0.6. Neap tide occurs around the 22-23 January. During the neap tide period the daily capacity factor fell to around 0.14 . The average capacity factor over the year was 0.48 , a significant increase on the 0.2 estimated in [31].

In contrast to the tidal power profile, the wind power profile was not cyclic on a diurnal timescale. In general periods of high or low resource were more prolonged than the tidal turbine power profile. For example, there was a $39 \mathrm{~h}$ period between 22-24 January when no wind power was generated, and a $56 \mathrm{~h}$ period from 26 January with $1.5 \mathrm{MW}$ of continuous wind power generation that exceeded the Alderney demand.

Alderney's demand showed diurnal variation, with greatest demand in the morning and evening. During this 2 week period the demand varies between 0.8-1.4 MW.

The monthly capacity factor of the tidal and wind turbine are displayed in Figure 6. The monthly energy produced by the tidal turbine remained stable at around $0.5 \mathrm{GWh}$, equivalent to a capacity factor of 0.48 . In contrast, the monthly wind turbine energy yield varies between $0.2-0.7 \mathrm{GWh}$, equivalent to monthly capacity factors of 0.2 (August) and 0.7 (February) respectively. In general, the wind turbine energy yield was highest in the autumn/winter months and reduced significantly in the summer months. The consequences of these differences in power production on hybrid system performance are explored further in the remainder of this paper. 
(a) Tidal stream power generation

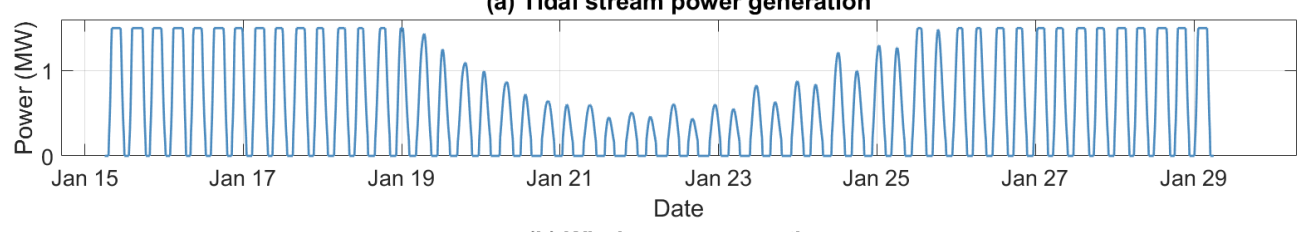

(b) Wind power generation

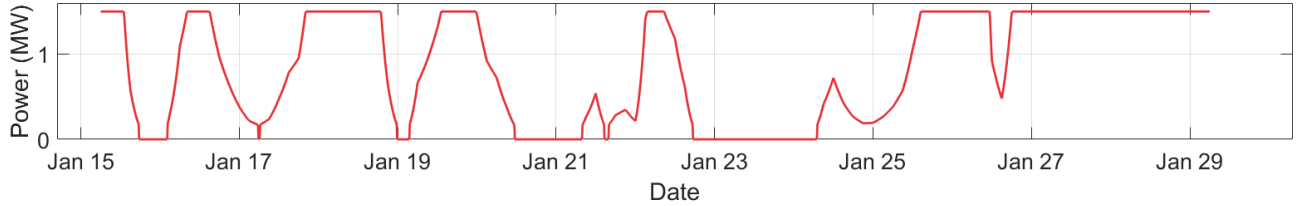

(c) Demand

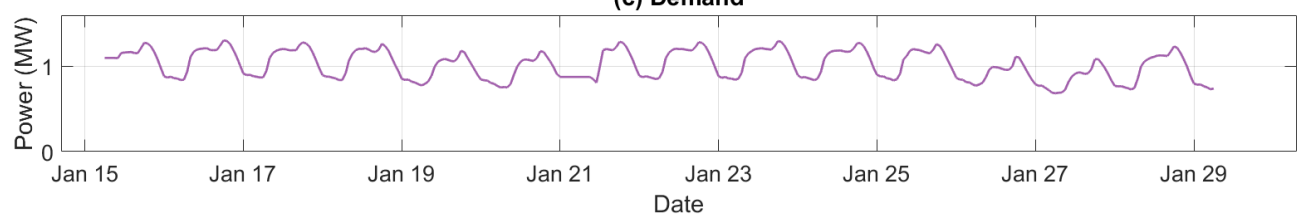

Figure 5. Two week power generation time-series from the (a) tidal stream turbine and (b) wind turbine, and (c) Alderney demand.

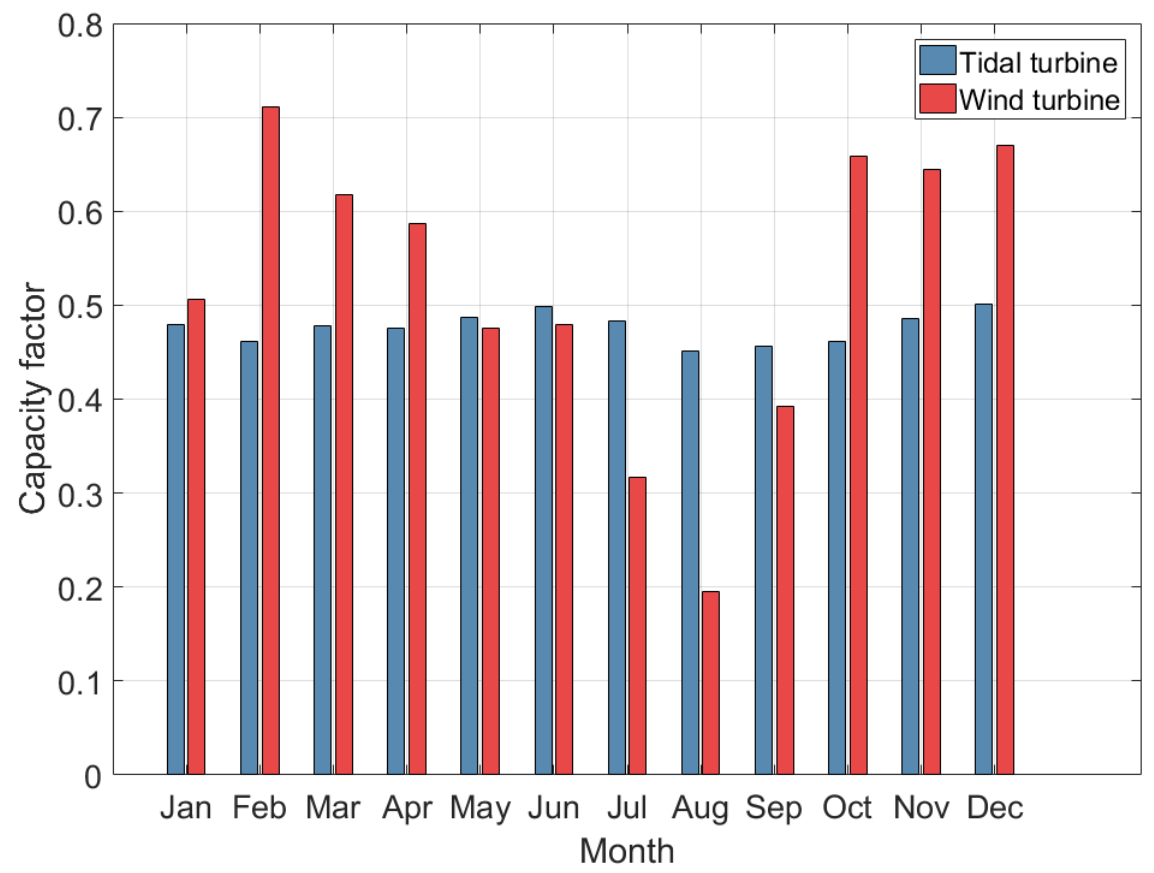

Figure 6. Monthly tidal and wind power capacity factors over 2013.

\subsection{Hybrid System Performance}

Figure 7 provides an overview of the operating behaviour of the hybrid systems. The annual time series of tidal and wind turbine power generation are plotted, alongside the power produced by the oil generators, and the demand profile. The same plots are also provided over a 28 day period spanning the end of November and the start of December 2013. In the THS, power production from the oil generators was used predominantly during neap tide periods to help meet demand when tidal power generation was low. There was also a noticeable increase in oil generated power in the winter months, when demand increased. Between May and November (i.e., when demand was at its lowest), during spring tide periods, the demand was met by the tidal power and the battery, with no reliance on the oil generators. During these periods, tidal power exceeded the demand, 
so excess turbine power was used to charge the battery. During slack tide, when the tidal turbine was not generating power, the demand was met by the battery. In contrast, the WHS used the oil generators at irregular intervals throughout the year to overcome low wind resource periods. This is shown in more detail in Figure 8.

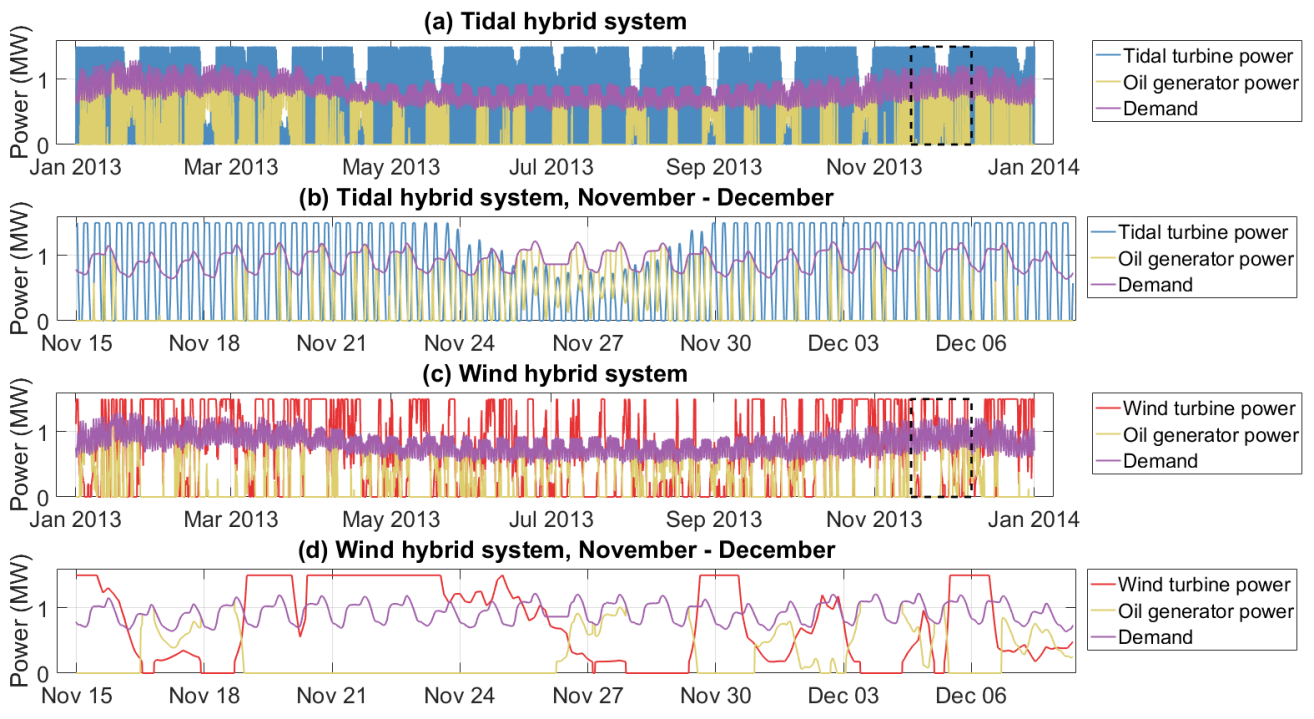

Figure 7. Turbine power, oil generator power and demand from the $(\mathbf{a}, \mathbf{b})$ tidal and $(\mathbf{c}, \mathbf{d})$ wind hybrid systems over periods spanning $2013(\mathbf{a}, \mathbf{c})$ and a 3 week period across November and December (b,d).

The WHS curtailed significantly more turbine energy than the THS as a result of the prolonged periods of high wind power generation. This is demonstrated in Figure 8. Between 15-18 March, both the tidal turbine and wind turbine were generating high levels of power (Figure 8a,d). In the case of the THS, during this period the battery was charged during each power cycle, and discharged during slack tide (Figure 8b). This prevented curtailment of turbine power because the battery never became fully charged, thereby allowing excess turbine power to charge the battery at all times. In the case of the WHS, as wind turbine power increased initially on the 15th March, the battery quickly charged to full capacity, (Figure 8e). The wind turbine power remained at $1.5 \mathrm{MW}$ for over 2 days. During this period the battery was unable to discharge, and so excess wind turbine power had to be curtailed (Figure 8f). This WHS behaviour was also seen late on the 21st March and early on the 24 March.

Figure 9 shows the monthly (a) curtailed turbine energy, (b) battery energy supplied to the grid and (c) energy from the oil generators supplied to the grid. Monthly curtailment was partly dependent on the level of turbine generation relative to the demand. The THS showed the highest turbine curtailment during the summer months, when demand was at its lowest. For the WHS, turbine curtailment was greatest during the winter months when the monthly wind resource was highest, even though demand was also highest during this period. The annual curtailment of the THS and WHS was $0.23 \mathrm{GWh}$ and $1.86 \mathrm{GWh}$ respectively. These levels of curtailment were equivalent to $4 \%$ and $27 \%$ of the annual turbine energy yield respectively.

Another way to assess the hybrid system's ability to use turbine energy (instead of curtailing) is through its 'failure to absorb', which is defined here as the number of $10 \mathrm{~min}$ time steps where the battery is fully charged and the demand is being met by the turbine, causing curtailment of turbine power. The THS had 3042 time steps $(6 \%$ of the year) where there was failure to absorb, whilst the WHS had 19,775 (38\% of the year), a $\times 6$ increase on the THS. The cyclic tidal power generation profile allowed the THS to supply the battery with significantly more turbine energy than the WHS, instead of it being curtailed. This is shown in Figure 9b, where the monthly energy supplied by the battery to the grid in the THS remained greater than $0.1 \mathrm{GWh}$, whilst in the WHS it was around $0.02 \mathrm{GWh}$. This 
demonstrated a level of incompatibility between wind power and short term storage, when considered in isolation.

a) Tidal hybrid system - turbine power generation
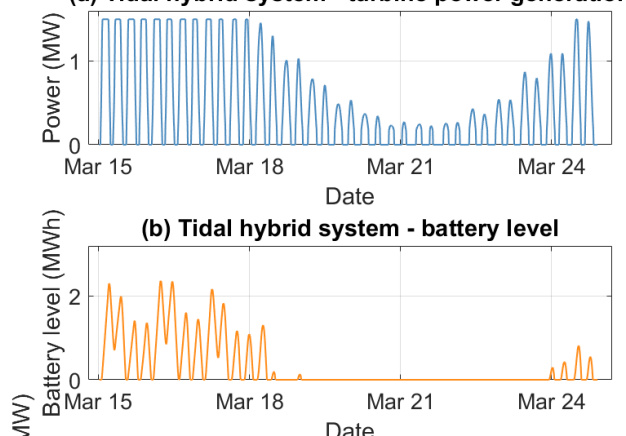

(c) Tidal hybrid system - curtailed turbine power

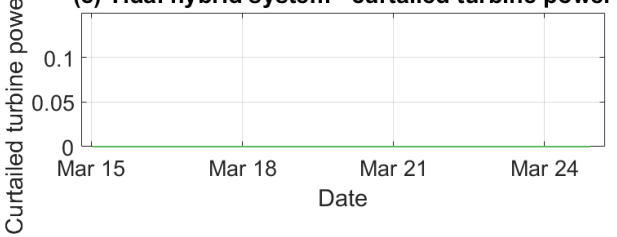

(d) Wind hybrid system - turbine power generation
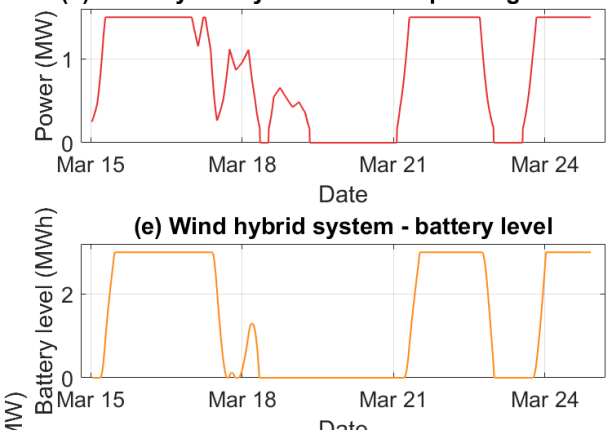

(f) Wind hybrid system - curtailed turbine powe

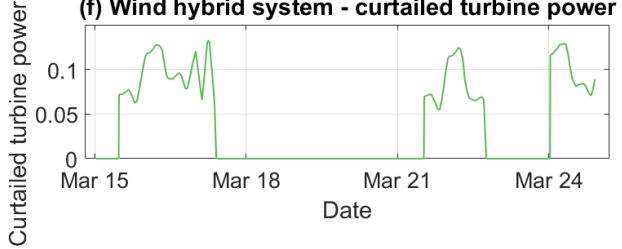

Figure 8. Overview of THS $(\mathbf{a}-\mathbf{c})$ and WHS $(\mathbf{d}-\mathbf{f})$, showing turbine power generation, battery level and curtailed power.

The monthly energy supplied by the oil generators to the grid is shown in Figure 9c. During low wind resource periods (i.e., summer months), the WHS relied heavily on the oil generators to meet the demand. The higher winter demand was offset somewhat by the higher levels of wind power generation. The WHS used oil generated power to meet $33 \%$ of Alderney's annual demand. In the THS, the higher winter demand resulted in the greatest oil generator use during these months. Energy from the oil generators was used to meet $22 \%$ of the annual demand.
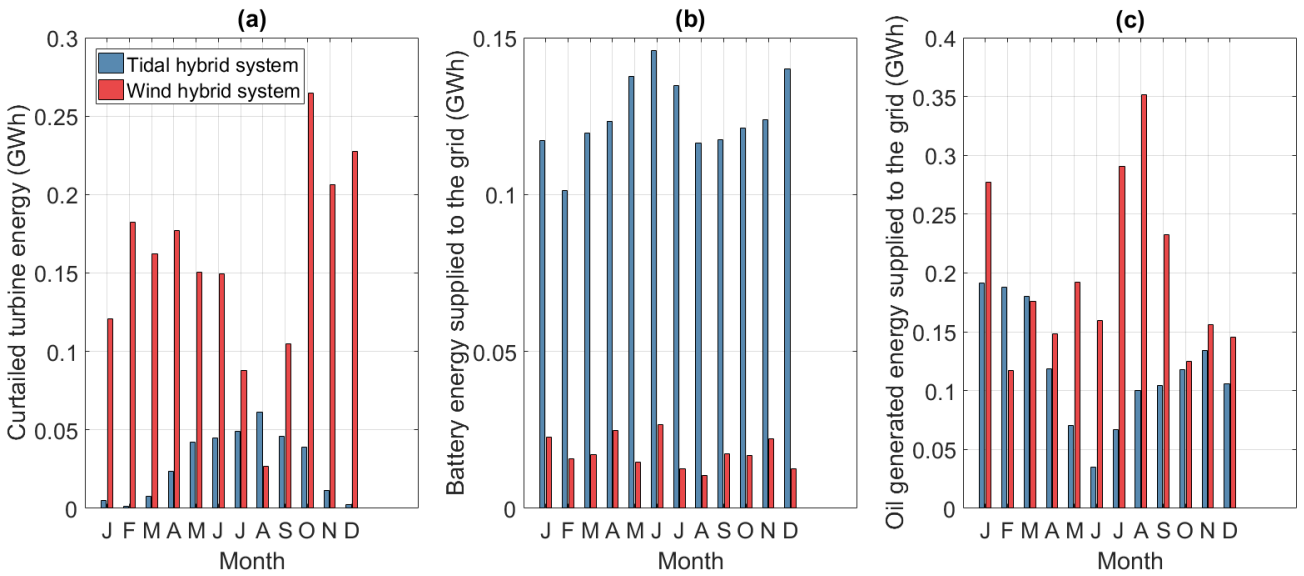

Figure 9. Comparison between THS and WHS (a) curtailed turbine power, (b) battery energy supplied to the grid and (c) oil generated energy supplied to the grid.

Figure 10 shows the annual energy fluxes between components in the THS and WHS. The tidal turbine produced $6.26 \mathrm{GWh}$, with a capacity factor of 0.48 . This was equivalent to $86 \%$ of Alderney's electricity demand. 0.23 GWh of the tidal energy was curtailed during periods when tidal power exceeded demand and the battery was fully charged. This was equivalent to $4 \%$ of the annual turbine energy yield. $1.87 \mathrm{GWh}$ of turbine energy was supplied to the battery during periods when turbine power exceeded demand and the battery had spare capacity. Of this $1.87 \mathrm{GWh}, 0.28 \mathrm{GWh}$ was lost due to the inefficiency 
of the battery. The remaining $1.59 \mathrm{GWh}$ was supplied by the battery to the grid during periods when demand was greater than tidal power generation. The tidal system relied on back-up oil generation to supply $1.58 \mathrm{GWh}$. This was equivalent to $22 \%$ of Alderney's annual electricity demand.

The wind turbine produced $6.83 \mathrm{GWh} /$ year, with a capacity factor of 0.52 . This was equivalent to $94 \%$ of Alderney's electricity demand. Only 0.26 GWh of wind energy was supplied to the battery, highlighting a high failure to absorb rate. This forced the WHS to curtail $1.86 \mathrm{GWh}$ of wind energy, which was equivalent to $25 \%$ of the wind turbine energy yield. The WHS used $2.40 \mathrm{GWh}$ of energy provided by the oil generator, a $52 \%$ increase on the THS. This was caused by the relatively long $(>2 \mathrm{~h})$ periods of low wind resource, which caused the battery to discharge and remain empty for long periods.

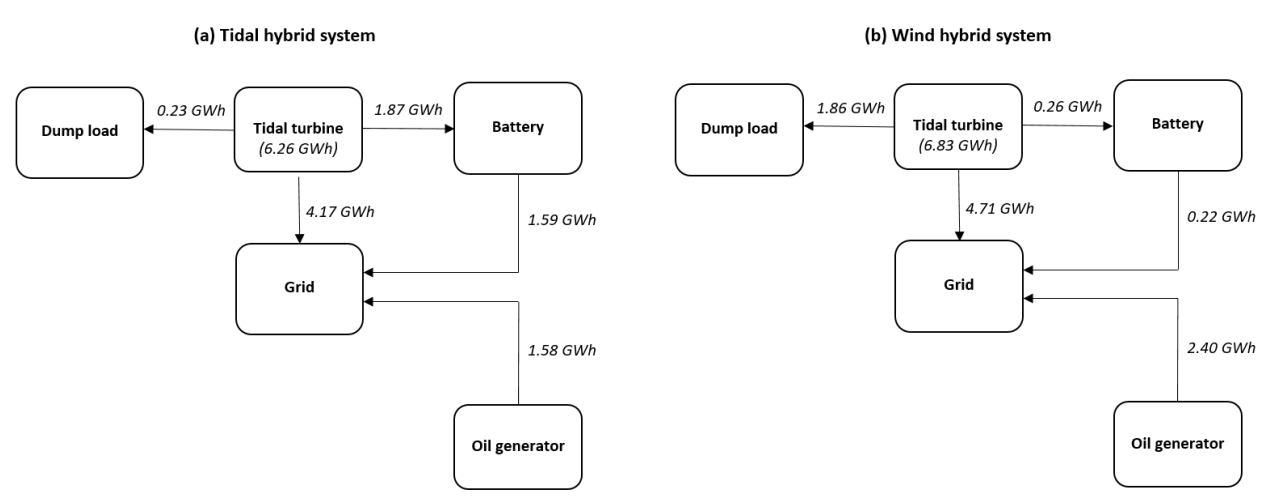

Figure 10. Annual energy flows in the (a) tidal and (b) wind energy systems.

Table 1 summarises the performance of the hybrid systems. The improvements to Alderney's electricity system by adding the tidal/wind turbine and battery are also tabulated. The THS reduced the supply of energy from oil generators by $5.72 \mathrm{GWh}$, relative to the current system. This was equivalent to a $78 \%$ reduction in oil usage. This oil saving provided a carbon emissions saving of $3.72 \times 10^{3}$ tonnes $\mathrm{CO}_{2}$ eq/year (also a $78 \%$ reduction). The WHS reduced Alderney's supply of energy from oil generators by $4.90 \mathrm{GWh}$, with a carbon emissions saving of $3.19 \times 10^{3}$ tonnes $\mathrm{CO}_{2}$ eq/year. This was equivalent to a $67 \%$ reduction in oil consumption and emissions. The annual carbon emissions of the THS was $1.03 \times 10^{3}$ tonnes $\mathrm{CO}_{2}$ eq/year. This was $0.53 \times 10^{3}$ tonnes $\mathrm{CO}_{2} \mathrm{eq} /$ year lower than that of the WHS, which emitted $1.56 \times 10^{3}$ tonnes $\mathrm{CO}_{2}$ eq/year.

The additional $0.82 \mathrm{GWh} /$ year of oil generated energy used in the WHS also incurred a financial cost, of $£ 254,200$ /year. Assuming a project life of 25 years, the total cost for the additional $0.82 \mathrm{GWh} /$ year provided by the oil generators was $£ 6.4$ million. This assumes the cost of energy from oil generators remains constant over the 25 year period. No discounting has been applied to take into account net present value of future cash flows.

It was found that by increasing the number of wind turbines in the WHS from one to three, the WHS would displace approximately the same amount of oil as the THS (with one tidal stream turbine). The economic viability of these systems was dependent on the capital expenditure (CapEx) and operating expenditure (OpEx) of the tidal stream and wind turbines and associated infrastructure. 
Table 1. Annual performance of the tidal and wind hybrid systems.

\begin{tabular}{|c|c|c|}
\hline Performance Metric & THS & WHS \\
\hline \multicolumn{3}{|l|}{ Turbine performance } \\
\hline Turbine energy yield & 6.26 GWh/year & $6.83 \mathrm{GWh} /$ year \\
\hline Capacity factor & 0.48 & 0.52 \\
\hline \multicolumn{3}{|l|}{ System performance } \\
\hline $\begin{array}{l}\text { Turbine energy supplied to the grid (di- } \\
\text { rectly) }\end{array}$ & 4.17 GWh/year & $4.71 \mathrm{GWh} /$ year \\
\hline Battery energy supplied to the grid & $1.59 \mathrm{GWh} /$ year & $0.22 \mathrm{GWh} /$ year \\
\hline Battery efficiency loss & $0.28 \mathrm{GWh} /$ year & $0.04 \mathrm{GWh} /$ year \\
\hline Curtailed turbine energy & $0.23 \mathrm{GWh} /$ year & 1.86 GWh/year \\
\hline Oil generated energy yield & $1.58 \mathrm{GWh} /$ year & $2.40 \mathrm{GWh} /$ year \\
\hline Failure to absorb & $6 \%$ of the year & $38 \%$ of the year \\
\hline Carbon emissions & $\begin{array}{l}1.03 \times 10^{3}+\mathrm{CO}_{2-} \\
\text { eq/year }\end{array}$ & $\begin{array}{l}1.56 \times 10^{3} \mathrm{t} \mathrm{CO}_{2-} \\
\text { eq/year }\end{array}$ \\
\hline \multicolumn{3}{|l|}{ Improvements by the hybrid systems } \\
\hline Reduction in oil generated energy & $5.72 \mathrm{GWh} /$ year & $4.90 \mathrm{GWh} /$ year \\
\hline Carbon emission saving & $\begin{array}{l}3.72 \times 10^{3}+\mathrm{CO}_{2-}^{-} \\
\text {eq/year }\end{array}$ & $\begin{array}{l}3.19 \times 10^{3}+\mathrm{CO}_{2-} \\
\text { eq/year }\end{array}$ \\
\hline 25 year carbon emission saving & $93.00 \times 10^{3} \mathrm{tCO}_{2}$-eq & $79.75 \times 10^{3} \mathrm{tCO}_{2}$-eq \\
\hline Reduction in cost of oil generated energy & $£ 1.77 \mathrm{~m} /$ year & $£ 1.52 \mathrm{~m} /$ year \\
\hline $\begin{array}{l}\text { Reduction in } 25 \mathrm{yr} \text { cost of oil generated } \\
\text { energy }\end{array}$ & $£ 44.3 \mathrm{~m}$ & $£ 38.0 \mathrm{~m}$ \\
\hline
\end{tabular}

\subsection{Battery Storage Capacity}

Figure 11 shows the relationship between battery storage capacity and (a) annual turbine energy curtailment, (b) annual dependency on oil generators, (c) 25 year oil cost and (d) 25 year carbon emissions $\left(\mathrm{CO}_{2}\right.$-eq). In the case of the THS, increasing the battery storage capacity from $1 \mathrm{MWh}$ to $2 \mathrm{MWh}$ enabled a higher proportion of the demand to be met by energy from the battery during slack tides, when the tidal turbine was not generating. This reduced curtailment significantly from $1.1 \mathrm{GWh}$ to $0.4 \mathrm{GWh}$ (Figure 11a). Increasing the battery storage capacity further resulted in diminishing returns on energy curtailment, as once the battery storage duration exceeds the duration of slack water, this main purpose of the battery (i.e., to help meet demand during slack tide) was served. In the case of the WHS, there was a gradual reduction in annual curtailment as battery storage duration is increased. Wind energy curtailment was consistently greater than tidal energy curtailment, regardless of battery storage capacity. For the WHS to reduce curtailment to the level of the THS $(0.23 \mathrm{GWh})$, it would need a battery with $160 \mathrm{MWh}$ storage capacity, equivalent to a battery storage duration of $107 \mathrm{~h}$. Lithium-ion battery storage is currently suitable for relatively short term storage applications up to around $4 \mathrm{~h}$. Hydrogen has the potential to provide longer term storage. Hydrogen is generated using electrolysis (powered by the turbine power) and converted back to electricity electrolysis using fuel cells. The round trip efficiency of this process is around $30 \%$ and is at a relatively early stage of development.

As discussed, in the case of the THS, the batteries ability to meet demand during the slack water periods was limited when the battery storage duration fell below the duration of slack tide. The remaining demand was met by oil generated energy (Figure 11b). The THS's reliance on the oil generators fell rapidly as battery storage capacity was increased from $1 \mathrm{MWh}$ for this reason. In the case of the WHS, increasing battery storage capacity helped enable the battery to meet demand during low wind periods also, but the sustained periods of low wind resource meant the battery durations considered in this work could 
not contribute significantly to bridge the relatively long periods of low wind resource. This resulted in the WHS having a greater reliance on the oil generators in general.

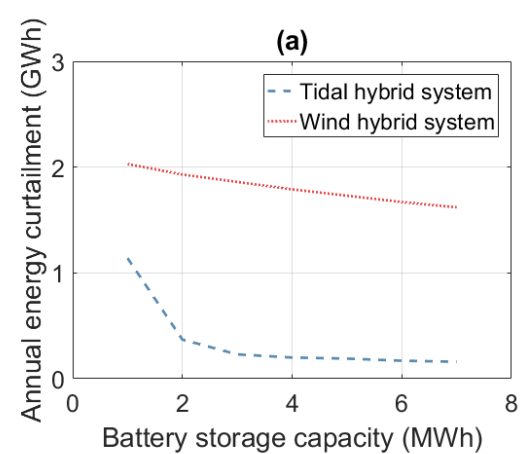

(c)

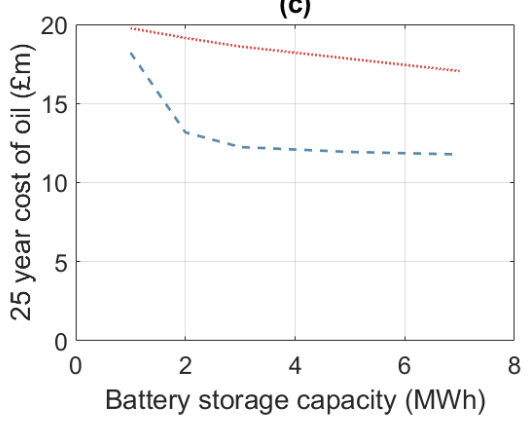

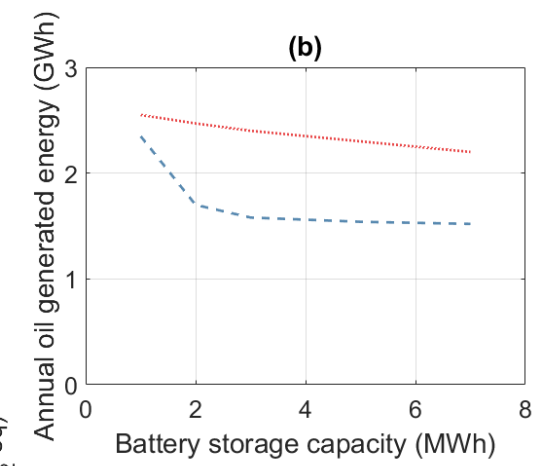

(d)

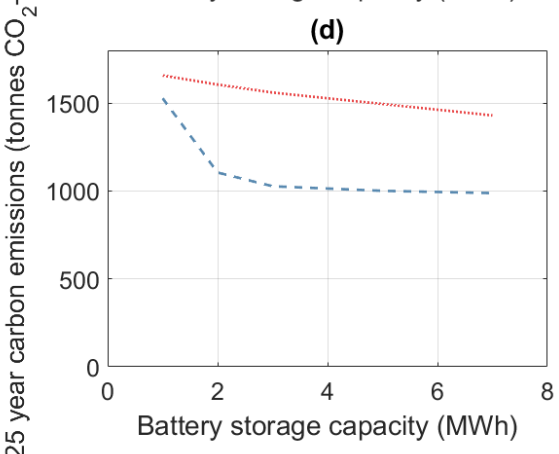

Figure 11. Relationship between battery storage duration and (a) annual turbine energy curtailment, (b) annual dependency on oil generators, (c) 25 year oil cost and (d) 25 year carbon emissions $\left(\mathrm{CO}_{2}\right.$-eq).

The cost of oil (Figure 11c) and carbon emissions from the oil generators (Figure 11d) were directly linked to the level of oil dependency of the systems. For this reason they also followed the same trend as curtailment and oil generated energy as battery storage capacity was increased. In the case of the THS, the 25 year oil cost was approximately $£ 7$ million less than the WHS once battery storage capacity exceeded $2 \mathrm{MWh}$. Oil prices can fluctuate significantly and are expected to rise over the assumed 25 years of the systems. This would widen the gap between THS and WHS oil expenditure further. Results suggested that when whole system costs were considered, the inclusion of tidal stream turbines in hybrid systems may become a financially viable option if the fuel cost saving outweighs the higher CapEx/OpEx tidal stream turbines will incur.

Once battery storage capacity exceeded $2 \mathrm{MWh}$, the THS emitted approximately 500 tonnes of $\mathrm{CO}_{2}$-eq less than the WHS (Figure 11d). This result highlighted that the WHS would require a significantly greater intervention to achieve zero emissions, such as a complimentary renewable power plant, for example. This would also come with an additional cost relative to the THS, since the THS would require a smaller additional plant.

\section{Conclusions}

This study compares the performance of tidal and wind hybrid systems used for supplying electricity to the island of Alderney. Results are presented for systems that use a 3 MWh battery, showing that the performance of the systems is dependent on the intermittent characteristics of the tidal and wind energy resource. The tidal resource provides four power cycles per day. This offers two main advantages over the WHS. First, slack water periods allow the battery to discharge, thereby allowing excess tidal power to charge the battery during the following tide. This cycle then repeats during the next tide, thereby minimising curtailment of turbine power. In contrast, high wind power periods are longer in duration, so the excess wind power initially charges the battery but is then 
curtailed once the battery has become fully charged. Subsequently the THS and WHS curtail $0.33 \mathrm{GWh} /$ year and $1.86 \mathrm{GWh} /$ year respectively. Secondly, during low resource periods the tidal turbine still generates some turbine power, limiting its reliance on the oil generators for back-up power to some extent. Low wind resource periods can last for days, with no power contribution provided by the wind turbine. This results in the WHS having a much higher reliance on the back-up oil generators, thereby reducing the level of autonomy of the WHS. The THS and WHS rely on $1.58 \mathrm{GWh} /$ year and $2.40 \mathrm{GWh} /$ year from the oil generators to meet the demand respectively.

The estimated cost impact of the WHS's higher reliance on energy from the oil generators is $£ 0.25$ million/year. This amounts to over $£ 6.4$ million if the project life is 25 years, oil prices remain at $0.31 £ / \mathrm{kWh}$ over this period and the net present value of future oil expenditure is assumed to remain unchanged. Given the THS's ability to displace more oil, it also achieves a greater reduction in carbon emissions over the WHS. This is directly related to the level of oil displacement, so the THS and WHS reduce carbon emissions by $77 \% /$ year and $68 \%$ /year respectively. It is found that for the WHS to displace the same amount of oil as the THS, two additional wind turbines would have to be added to the system. The financial viability of the THS and WHS will depend on the CapEx/OpEx of the tidal and wind turbines, which is out of the scope of this work.

The sensitivity of system performance to battery storage capacity was also investigated. The THS shows significant performance improvement as the battery storage capacity is increased from $1 \mathrm{MWh}$ to $3 \mathrm{MWh}$. This increase enables the battery to discharge power to meet demand over the majority of the spring slack water periods. Increasing battery capacity further results in diminishing returns, as the battery's main purpose to provide power to the grid during slack tides has been fulfilled. The WHS shows a gradual improvement in performance as battery storage capacity is increased, however the THS consistently outperforms the WHS by displacing more oil, regardless of battery storage capacity.

Author Contributions: Conceptualization, D.C., A.A.; methodology, D.C.; software, D.C. and Z.G.; validation, D.C., A.A., Z.G. and J.M.; formal analysis, D.C.; investigation, D.C.; resources, D.C. and Z.G.; data curation, D.C.; writing — original draft preparation, D.C.; writing—review and editing, A.A, Z.G., J.M.; visualization, D.C.; supervision, A.A., J.M.; project administration, D.C., J.M.; funding acquisition, J.M. All authors have read and agreed to the published version of the manuscript.

Funding: D.C. and J.M. acknowledge the support of the Tidal Stream Industry Energiser project (TIGER), co-financed by the European Regional Development Fund through the INTERREG France (Channel) England Programme. AA acknowledges the support of NERC through the Industrial Innovation fellowship grant NE/R013209/2. Z.G. acknowledges the support of Engineering and Physical Sciences Research Council (EPSRC) Centre for Doctoral Training in the Mathematics of Planet Earth [grant number EP/L016613/1]. JM also acknowledges the support of the INTERREG France Channel England (FCE) European Commission Intelligent Community Energy (ICE) project.

Acknowledgments: Thanks to Peter Fraenkel for useful discussions that helped form parts of this research.

Conflicts of Interest: The authors declare no conflict of interest.

\section{References}

1. Clarke, J.A.; Connor, G.; Grant, A.D.; Johnstone, C.M. Regulating the output characteristics of tidal current power stations to facilitate better base load matching over the lunar cycle. Renew. Energy 2006, 31, 173-180. [CrossRef]

2. Bryden, I.G.; Macfarlane, D.M. The utilisation of short term energy storage with tidal current generation systems. Energy 2000, 25, 893-907. [CrossRef]

3. Barbour, E.; Bryden, I.G. Energy storage in association with tidal current generation systems. Proc. Inst. Mech. Eng. Part A J. Power Energy 2011, 225, 443-455. [CrossRef]

4. Manchester, S.; Barzegar, B.; Swan, L.; Groulx, D. Energy storage requirements for in-stream tidal generation on a limited capacity electricity grid. Energy 2013, 61, 283-290. [CrossRef]

5. Eigg Electric Ltd. Eigg Electric. Available online: http://isleofeigg.org/eigg-electric/ (accessed on 15 December 2020).

6. Bhave, A.G. Hybrid solar-wind domestic power generating system - A case study. Renew. Energy 1999, 17, 355-358. [CrossRef] 
7. Elhadidy, M.A.; Shaahid, S.M. Parametric study of hybrid (wind + solar + diesel) power generating systems. Renew. Energy 2000, 21, 129-139. [CrossRef]

8. Elhadidy, M.A.; Shaahid, S.M. Promoting applications of hybrid (wind+photovoltaic+diesel+battery) power systems in hot regions. Renew. Energy 2004, 29, 517-528. [CrossRef]

9. Perera, A.T.; Attalage, R.A.; Perera, K.K.; Dassanayake, V.P. Designing standalone hybrid energy systems minimizing initial investment, life cycle cost and pollutant emission. Energy 2013, 54, 220-230. [CrossRef]

10. Gan, L.K.; Shek, J.K.; Mueller, M.A. Hybrid wind-photovoltaic-diesel-battery system sizing tool development using empirical approach, life-cycle cost and performance analysis: A case study in Scotland. Energy Conver. Manag. 2015, 106, 479-494. [CrossRef]

11. Friedrich, D.; Lavidas, G. Evaluation of the effect of flexible demand and wave energy converters on the design of hybrid energy systems. IET Renew. Power Gener. 2017, 11, 1113-1119. [CrossRef]

12. Rashid, K.; Safdarnejad, S.M.; Powell, K.M. Dynamic simulation, control, and performance evaluation of a synergistic solar and natural gas hybrid power plant. Energy Conver. Manag. 2019, 179, 270-285. [CrossRef]

13. Notton, G.; Muselli, M.; Louche, A. Autonomous hybrid photovoltaic power plant using a back-up generator: A case study in a mediterranean island. Renew. Energy 1996, 7, 371-391. [CrossRef]

14. Fusco, F.; Nolan, G.; Ringwood, J.V. Variability reduction through optimal combination of wind/wave resources-An Irish case study. Energy 2010, 35, 314-325. [CrossRef]

15. Karimirad, M.; Koushan, K. WindWEC: Combining wind and wave energy inspired by hywind and wavestar. In Proceedings of the IEEE International Conference on Renewable Energy Research and Applications (ICRERA), Birmingham, UK, 20-23 November 2016; pp. 96-101.

16. Blunden, L.; Bahaj, A. Tidal energy resource assessment for tidal stream generators. Proc. Inst. Mech. Eng. Part A J. Power Energy 2007, 221, 137-146. [CrossRef]

17. Carballo, R.; Iglesias, G.; Castro, A. Numerical model evaluation of tidal stream energy resources in the Ría de Muros (NW Spain). Renew. Energy 2009, 34, 1517-1524. [CrossRef]

18. Adcock, T.A.; Draper, S.; Nishino, T. Tidal power generation - A review of hydrodynamic modelling. Proc. Inst. Mech. Eng. Part A J. Power Energy 2015, 229, 755-771. [CrossRef]

19. Lewis, M.; Neill, S.; Robins, P.; Hashemi, M. Resource assessment for future generations of tidal-stream energy arrays. Energy 2015, 83, 403-415. [CrossRef]

20. Nova Innovation. Bardsey Island, Wales. Available online: https://www.novainnovation.com/bardsey-island (accessed on 20 November 2020).

21. Nova Innovation. A World-First for Nova Innovation: The 'Holy Grail' of Baseload Tidal Power. Available online: https: //www.novainnovation.com/post/a-world-first-for-nova-innovation-the-holy-grail-of-baseload-tidal-power (accessed on 20 November 2020).

22. European Marine Energy Centre. Press Release: Flow Batteries to Combine with Tidal Power to Produce World's First Continuous Green Hydrogen. Available online: http:/ / www.emec.org.uk/flow-batteries-combine-with-tidal-power-to-produce-greenhydrogen/ (accessed on 20 November 2020).

23. Coles, D.; Blunden, L.; Bahaj, A. Assessment of the energy extraction potential at tidal sites around the Channel Islands. Energy 2017, 124, 171-186. [CrossRef]

24. Simonsen, K.; Niclasen, B.A. Analysis of the energy potential of tidal streams on the Faroe Shelf. Renew. Energy 2021, 163, 836-844. [CrossRef]

25. Coles, D.; Walsh, T.; Kyozuka, Y.; Oda, Y. Tidal turbine array design and energy yield assessment for Naru Strai , Japan. In Proceedings of the 4th Asian Wave and Tidal Energy Conference, Taipei, Taiwan, 9-13 September 2018.

26. Waldman, S.; Yamaguchi, S.; O'Hara Murray, R.; Woolf, D. Tidal resource and interactions between multiple channels in the Goto Islands, Japan. Int. J. Mar. Energy 2017, 19, 332-344. [CrossRef]

27. Energy Saving Trust. Supporting the Development of the States of Alderney Island Energy Policy; Technical Report; Energy Saving Trust: London, UK, 2013.

28. AEA Group. Strategic Tidal Stream Assessment for Alderney; Technical Report; AEA Group: Birmingham, AL, USA, 2014.

29. Parliamentary Office of Science and Technology. CArbon Footprint of Electricity Generation; Technical Report; Parliamentary Office of Science and Technology: London, UK 2006.

30. Jaguaribe, C. Study to Convert the Island of Alderney Into a Green Island; Technical Report; Cranfield University: Cranfield, UK, 2012.

31. Balsells, A. Management of the Electricity Supply in Alderney School. Ph.D. Thesis, Cranfield University, Cranfield, UK, 2015. [CrossRef]

32. Black and Veatch. Lessons Learnt from MeyGen Phase 1A Final Summary Report; Technical Report; Meygen Ltd.: Inner Sound/Pentland Firth, Scotland 2020.

33. Goss, Z.L.; Coles, D.S.; Piggott, M.D. Identifying economically viable tidal sites within the Alderney Race through optimization of levelized cost of energy: Economic viability of the Alderney Race. Philos. Trans. R. Soc. A Math. Phys. Eng. Scie. 2020, 378. [CrossRef]

34. Soulsby, R. Tidal-Current Boundary Layers. In The Sea; Wiley: Hoboken, NJ, USA, 1990; Volume 9, pp. $523-566$.

35. Bahaj, A.S. Generating electricity from the oceans. Renew. Sustain. Energy Rev. 2011, 15, 3399-3416. [CrossRef] 
36. Slivinski, L.C.; Compo, G.P.; Whitaker, J.S.; Sardeshmukh, P.D.; Giese, B.S.; McColl, C.; Allan, R.; Yin, X.; Vose, R.; Titchner, H.; et al. Towards a more reliable historical reanalysis: Improvements for version 3 of the Twentieth Century Reanalysis system. Q. J. R. Meteorol. Soc. 2019, 145, 2876-2908. [CrossRef]

37. Windfinder. Yearly Wind and Weather Averages for Alderney Airport. Available online: https://www.windfinder.com/ windstatistics/alderney (accessed on 25 November 2020).

38. Telsa. Megapack. Available online: https://www.tesla.com/en\{_\}gb/megapack (accessed on 15 December 2020)

39. Elexon. Elexon Portal. Available online: https://www.elexonportal.co.uk/news/latest?cachebust=fi2ipbpqo5 (accessed on 25 November 2020).

40. University of Sheffield. Live PV Generation. Available online: https://www.solar.sheffield.ac.uk/pvlive/ (accessed on 25 November 2020).

41. Gridwatch. G.B National Grid Status. Available online: https://www.gridwatch.templar.co.uk/ (accessed on 25 November 2020).

42. Pugh, D. Tides, Surges and Mean Sea-Level; John Wiley \& Sons: Chichester, UK 1996.

43. Met Office. What Is a Jet Stream? Available online: https://www.metoffice.gov.uk/weather/learn-about/weather/typesof-weather/wind/what-is-the-jet-stream\#: :text=The $\% 20$ jet $\% 20$ stream $\% 20$ is $\% 20$ a,blowing $\% 20$ from $\% 20$ west $\% 20$ to $\% 20$ east (accessed on 20 January 2020). 